\title{
The Association of Organizational Commitment and Personal Factor With Burnout Syndrome and Turnover Intention in Nurses
}

Indonesian Nursing Journal of Education and Clinic (INJEC)

I58- 165

Volume 5, Issue 2, December 2020

DOI: 10.24990/injec.v5i2.318

injec.aipni-ainec.org/index.php/INJEC/index

Received : 2020-07-24

Accepted : 2020-08-25

The Association of Indonesian Nurse

Education Center (AINEC)

\author{
Nursalam Nursalam ${ }^{10}$, Shintia Ekawati', Andri Setiya Wahyudi
}

\begin{abstract}
Introduction: Turnover intention has many negative impacts on hospitals. The purpose of this research was to analyze the relationship between organizational commitment, personal factors and burnout syndrome to turnover intention in nurses.

Methods: A descriptive analytic with cross-sectional approach, the sample was 83 nurses in type $C$ hospital in Lamongan based on a cluster random sampling. The variables were organizational commitment, personal factor, burnout syndrome and turnover intention. Organizational commitment was measured with a modified questionnaire from Meyer and Allan, personal factors measured using demographic questionnaire, Maslach Burnout Inventory for burnout syndrome and modified questionnaire from Chen and Francesco for turnover intention. Moreover, the analysis uses ordinal regression statistical and logistic regression.

Results: The results showed that the commitment factor continuance $(p=0.00 \mathrm{I})$, normative commitment $(p=0.000)$, education $(p=0.024)$, emotional fatigue $(p=0.008)$ and attitude $(p=$ 0.008 ) had a significant relationship with burnout syndrome. Emotional exhaustion has significant relationship with turnover intention after adjusted with depersonalization and self-achievement $(\mathrm{P}=$ 0.008).
\end{abstract}

Conclusion: It can be concluded that nurses in the Type $C$ hospital can be loyal to reduce the turnover number, and this can increase the health levels of Indonesian people.

\section{Keywords}

burnout syndrome, nurse, organization, turnover intention

\section{INTRODUCTION}

Nurse turnover is one of the challenges of hospital human resource management (Claramita et al., 2016; VanFosson, Jones and Yoder, 2016). This turnover will certainly have an impact, both on hospital management and the quality of service (Fan et al., 20I5; Kim and Suh, 2018). For hospitals, the high level of turnover of nurses tends to lead to staff losses, additional recruitment costs for new nurses, job placement, and even job training for new nurses (Wong, Cummings and Ducharme, 20I3). Based on a previous detailed survey of many type $C$ hospital nurses in the Lamongan district on 5 February, 2020, type C hospitals in Lamongan Regency will be used as research sites, namely Nashrul Ummah Hospital and Citra Medika Hospital, to find out the level of

\footnotetext{
${ }^{1}$ Faculty of Nursing, Universitas Airlangga, Surabaya - Indonesia

Corresponding Author:

Nursalam Nursalam, Faculty of Nursing, Universitas Airlangga, Surabaya - Indonesia

Universitas Airlangga Kampus C, Jl. Mulyorejo, Mulyorejo, Surabaya, Kota SBY, Jawa Timur 60II 5

Email: nursalam@fkp.unair.ac.id
} 
turnover in these hospitals. The turnover level intention in each of these hospitals is at least one nurse per year. Thus, it can be seen that the percentage of turnover in this type C hospital in the last three years from 2017 to 2019 has reached 12 percent.

Turnover becomes one of the last choices for a nurse if they find that his/her working conditions are no longer what they had expected (Winasih, Nursalam and Kurniawati, 2015; Abuaddous, Al Sokkar and Abualodous, 2018a). Gibson (1987) theoretically explained that a person's behavior and performance are influenced by three factors, namely individual factors, psychological factors, and organizational factors, which may affect the frequency of turnover of nurses. Individual factors that affect a person's behavior and performance include skills and abilities, background, and demographics, while psychological factors include attitudes, motivation, perception, personality, and learning patterns (Gibson, 2006). Gibson also stated that demographic variables are factors that influence individual behavior and performance (Phiri, Heyns and Coetzee, 2020). Despite these causative factors, several factors are considered to have a significant relationship, namely marital status, length of employment, social support, family structure, responsibilities, emotional stability, and exhaustion clarity, all of which can cause burnout syndrome (Beauvais et al., 20I I).

Previous research shows that organizational commitment has an important role in influencing the incidence of burnout syndrome in critical room care (Ramírez et al., 2018). The high workload also affects the organizational commitment of health workers. According to research conducted in developed countries (Pracana, 20l4), personal factors that exist in health workers, such as motivation and knowledge, provide a high contribution to the incidence of burnout syndrome (Kim et al., 2018). This will have an impact on changes in the turnover intention of health workers in meeting the needs of nursing care for patients at the hospital (Thumm, 2017). Some of the factors obtained are based on the results of previous research; however, in Indonesia there are still not many studies that discuss the incidence of burnout syndrome and turnout intention, so further research is needed.
In regard to the negative impact of burnout syndrome and turnover intention for hospital management and service quality, an assessment of organizational commitment, personal factors and burnout syndrome is very important (Abuaddous, Al Sokkar and Abualodous, 2018b). This is in line with the theory put forward by Meyer, Gibson and Maslach where the occurrence of turnover intention is caused by several things, namely organizational commitment, which includes affective commitment, continuance commitment and normative commitment; besides organizational commitment, according to Gibson (2006) there are also personal factors, which include demographics, attitudes and motivations, whereby both organizational commitment and personal factors can cause burnout syndrome (Gibson, 2006). The aim of this study was to analyze the relationship between organizational commitment, personal factors and burnout syndrome to turnover intention in nurses.

\section{MATERIALS AND METHODS}

This research used a descriptive-analytic with a cross-sectional approach and took place in March 2020; the sample of this research included 83 nurses selected by simple random sampling at the Type C Hospital in Lamongan Regency. The sample criteria were nurses that have minimum six years job experience and giving care in hospital ward and all nurses completed an informed consent before research was conducted. The variable of this research used organization commitment and personal factor for independent variables and the dependent variables were burnout syndrome and turnover intention. Data were collected using questionnaire, organizational commitment was measured with a modified questionnaire from Meyer and Allan (Rahman, Ferdausy and Karan, 2017) using evaluation a 5 -point Likert- scale (very poor to very good) with the scores varied from I to 5 . The personal factors were measured using demographic questionnaire (Ribeiro et al., 2014) and burnout syndrome variable was measured using Maslach Burnout Inventory (MBI) (Leiter and Maslach, 20I6). The last variable, turnover intention, was measured using modified questionnaire from Chen and Francesco for turnover intention (Lu et al., 
2017). The instrument was tested for validity and reliability before data collection was conducted, and the results showed that all instruments were valid; all questionnaires showed Pearson correlation $0.534-1.0$ and the Cronbach's alpha of organizational commitment was 0.964, turnover intention was 0.770 and burnout syndrome instrument was 0.964 . The study was conducted using a questionnaire given to respondents who signed the informed consent without coercion.
Respondents' answers were collected directly, the collected data were then validated and descriptive and inferential analyses were performed. Data were collected and analyzed using the Logistic Regression Test with $\alpha: 0.05$. This study was approved by the ethical committee Faculty of Nursing, Universitas Airlangga with number 1934-KEPK dated March 6, 2020.

Table I. Distribution of respondents' characteristics

\begin{tabular}{llll}
\hline Variable & Category & $\mathbf{N}$ & $\mathbf{\%}$ \\
\hline \multirow{3}{*}{ Age } & Junior middle worker & 2 & 2.4 \\
& Early prime worker & 33 & 39.8 \\
\multirow{3}{*}{ Gender } & Middle prime worker & 24 & 28.9 \\
& Primary worker & 24 & 28.9 \\
& Male & 33 & 39.8 \\
Education & Female & 50 & 60.2 \\
& SPK & 0 & 0.0 \\
& Diploma & 63 & 75.9 \\
& Bachelor & 20 & 24.1 \\
\hline
\end{tabular}

Table 2. Variable Distribution of Respondents

\begin{tabular}{llcc}
\hline Variable & Category & $\mathbf{N}$ & $\mathbf{\%}$ \\
\hline \multirow{2}{*}{ Affective Commitment } & Low & 2 & 2.4 \\
& Medium & 60 & 72.3 \\
Continuance & High & 21 & 25.3 \\
Commitment & Low & 5 & 6.0 \\
& Medium & 72 & 86.7 \\
Normative & High & 6 & 7.2 \\
Commitment & Low & 16 & 19.3 \\
Motivation & Medium & 62 & 74.7 \\
& High & Low & 6.0 \\
Attitude & Medium & 5 & 6.0 \\
& High & 5 & 72.3 \\
& Low & 60 & 21.7 \\
Burnout Syndrome & Medium & 18 & 7.2 \\
& High & 6 & 57.8 \\
Emotional & Low & 48 & 34.9 \\
Exhaustion & Medium & 29 & 79.5 \\
& High & 66 & 13.3 \\
Depersonalization & Low & 11 & 7.2 \\
& Medium & 6 & 77.1 \\
Turnover Intention & High & 64 & 16.9 \\
\hline & Low & 14 & 6.0
\end{tabular}


Table 3. The hypothesis analysis and relationship of variable

\begin{tabular}{|c|c|c|c|c|c|c|}
\hline \multirow[b]{2}{*}{ Variable } & \multirow[b]{2}{*}{ Estimation } & \multirow[b]{2}{*}{ Std. Error } & \multirow[b]{2}{*}{ Wald } & \multirow[b]{2}{*}{ Sig } & \multicolumn{2}{|c|}{ 95\% Confidence Interval } \\
\hline & & & & & $\begin{array}{l}\text { Lower } \\
\text { Bound }\end{array}$ & Upper Bound \\
\hline $\begin{array}{l}\text { Affective } \\
\text { commitment }\end{array}$ & 13.831 & 9161.47 & 0.000 & 0.999 & -17942 & 17970 \\
\hline $\begin{array}{l}\text { Continuance } \\
\text { commitment }\end{array}$ & 14.643 & 4.612 & 10.079 & 0.001 & 5.603 & 23.684 \\
\hline $\begin{array}{l}\text { Normative } \\
\text { Commitment }\end{array}$ & 18.796 & 0.979 & 368.304 & 0.000 & 16.876 & 20.715 \\
\hline Age & 0.288 & 7840.91 & 0.000 & 1.000 & -15368 & 15368.2 \\
\hline Gender & 0.714 & 0.806 & 0.784 & 0.376 & -0.866 & 2.294 \\
\hline Education & -1.817 & 0.805 & 5.091 & 0.024 & -3.396 & -0.239 \\
\hline Motivation & 3.679 & 2.331 & 2.492 & 0.114 & -0.889 & 8.246 \\
\hline Attitude & 5.323 & 1.992 & 7.140 & 0.008 & 1.419 & 9.228 \\
\hline
\end{tabular}

Table 4. The hypothesis results of turnover intention

\begin{tabular}{lllllll}
\hline Variable & B & S.E & Wald & Sig & Exp(B) & \multicolumn{2}{c}{ 95\% Confidence Interval } \\
\cline { 6 - 7 } & & & & & Lower Bound & Upper Bo \\
\hline Emotional exhaustion & & 9.560 & .008 & & 4.302 & 17.681 \\
Depersonalization & & .224 & .894 & & -12.651 & 12.970 \\
Self-achievement & & 1.280 & .527 & & -7.253 & 7.970 \\
\hline
\end{tabular}

was emotional exhaustion $(p=0.008)($ Table

\section{RESULTS}

The distribution of respondents in Table I shows that the average age was in early prime worker with 33 respondents (39.8\%). Meanwhile, in terms of gender, the majority was female $(60.2 \%)$ and the level of education of most nurses was diploma degree $(75.9 \%)$.

Based on Table 2 as a variable distribution, the affective, continuance, normative commitment, motivation and attitude showed in the medium category. Meanwhile, emotional exhaustion in burnout syndrome was in low category (77.1\%) and low category also showed in depersonalization (81.9\%). The self-achievement was in low category (54.2\%) and as many as $63(75.9 \%)$ respondents have no intention to turnover.

The continuance of commitment factor, normative commitment, education, and attitude have a significant relationship with burnout syndrome where the $p$ value was $<0.05$. After adjusted with logistic regression, the most dominant factor relation was normative commitment $(p=0.000)$ (Table 3). In the turnover intention after adjusted with emotional exhaustion, depersonalization and self-achievement, it showed that the most dominant factor influencing turnover intention
4).

\section{DISCUSSIONS}

\section{Relationship between Organizational Commitment Factors and Burnout Syndrome}

Based on the results of the study, respondents who have a high level of continuance commitment and normative commitment are also at a high level of burnout syndrome. This is because respondents who are trusted and given more job responsibilities than other employees get a feeling of stress from their work that triggers burnout for them (Shanafelt and Noseworthy, 2017). Burnout syndrome is a response to emotionally demanding services requiring the help, assistance, attention, and treatment of nurses as service providers. The commitment of healthcare providers to the organization has a strong impact on the quality of treatment provided to the patient. There is a significant relationship between the organization's commitments to the variety of work, which will determine the individual experiencing burnout syndrome. Organizational commitment is more able to deal with complex work variations. It will affect the individual in how to address and pass through burnout syndrome 
(Kalani et al., 2018). Moreover, organizational commitment also has an impact on the nurses' performances, especially when they get work exhaustion, which may lead to burnout syndrome. This study showed that organizational commitment is an important factor in an attempt to reduce or prevent burnout syndrome. Nurses with a high level of organizational commitment tend to be more able in responding to work exhaustion, so they can easily avoid burnout.

\section{Relationship \\ between \\ (Demographics) Factors \\ Personal Syndrome}

The average age of working nurses is in the productive age. Nurses who are in the productive age tend to have stronger physical and higher morals. This also indicates that the younger the age of workers, the higher the level of work pressure because they lack work experience (Kilgo, Ezell Sheets and Pascarella, 2015). According to Byrne, burnout mostly affects young workers under the age of 30 or 40 who have relatively little work experience. It is arguable that most young workers are filled with unrealistic expectations compared to the older ones. As we get older, individuals become more mature, more emotionally stable, and more firm, with a more realistic mentality (Zelenik, Peršuh and Jordan, 2016). Age is defined as work experience so that burnout appears as an initial risk to one's career. The workers' age, which is a personal factor (demographic), tends to have a relationship with burnout faced by individuals. This is because age is one of the determinants of individuals experiencing exhaustion at work, which will result in a burnout effect. Every age has different levels of ability to think and adapt in which it influences the work behavior (Prendergast, Ketteler and Evans, 2017).

The education a nurse has to hold as a worker in the hospital has been set as the appropriate standard in qualifications. This is in line with previous research which stated that the higher the education level of a nurse, the higher the nature of critical thinking, mature logic, and systematic thinking by which it will improve the quality of nurse performance (Ríos-Risquez and García-Izquierdo, 2016). Nurses who hold a higher education level will work more professionally than nurses graduating from the diploma. They are expected to have higher critical thinking ability and be far more mature when compared to diploma nurses. A higher level of education will lead to higher demand and a lower incidence of burnout syndrome, due to the better professionalism of nurses. This has an impact on higher turnover intentions as well. There is no relationship between the genders of respondents to burnout syndrome. The results of this study are also consistent with prior research which has pointed out that there is no significant relationship between gender and burnout syndrome (De Paiva et al., 2017).

As much as gender, motivation also has no significant effect on burnout syndrome; the results of the study are in line with the findings conducted by Setiawati, which stated that motivation does not have a significant effect on burnout syndrome and the performance of nurses. Good nurses' performance is not only because of motivational factors, but more factors significantly influence their performance, such as rewards, workload, experience, and the age of each nurse. $A$ job is going to run well when someone has a good desire to finish the job (Vidotti et al., 20l8).

Attitude has a significant impact on burnout syndrome, this is due to one of the nurses who has completed his/her nursing care before going home and the number of patients is not very high. Attitude is mental alertness that can be learned and organized from experience and has an impact on how to respond to other people, objects, and situations. The finding in the previous research stated that there is a significant negative relationship between the attitude of burnout syndrome among workers (Lestander, Lehto and Engström, 2016; Valero-Chillerón et al., 2019). This means that, if someone has a negative attitude toward career developments, then he/she will be in high probability to get a high level of burnout. Otherwise, if someone can bring a positive attitude toward his/her career development, he/she will never give up on achieving his/her goals. As a result, the probability to get burnout will be low.

Burnout syndrome and work stress are significantly relevant to the context of turnover; it has a major impact on turnover intention. Moreover, previous research has indicated that the level of burnout at work has a positive and significant effect on the intention 
for turnover. A higher level of burnout may increase the employees' intention to turnover. One of the reasons someone experiences distress and burnout is the working life. If an employee is not able to work well and dynamically, he/she will eventually lose control. This may have negative effects on her/himself. Finally, the pressure of working life and burnout can lead employees to turnover or to move to another workplace (Arrogante and Aparicio-Zaldivar, 2017).

\section{Relationship between Burnout Syndrome and Turnover Intention}

Burnout syndrome is not only related to a single factor, but appears as a result of the interaction between several factors. Burnout syndrome arises as a result of increased emotional exhaustion, depersonalization and decreased selfachievement (Rodrigues, Santos and Sousa, 2017). Burnout is a state of physical, emotional and mental fatigue caused by continuous stressful situations; one of the causes of turnover intention is burnout syndrome (De Oliveira et al., 2018). The level of job burnout has a positive and significant effect on turnover intention. A higher level of job burnout can increase employee turnover intention. The results of this study are supported by research which shows that job burnout has a positive and significant effect on turnover intention. Burnout syndrome is a psychological response to stress at work and causes undesirable results, such as reduced employee performance, shifts in time spent on work-related activities or non-work activities, lower organizational commitment, increased absenteeism and turnover intention.

Limitations of the study obtained from this study are that it has still not answered all the factors that influence burnout syndrome and cannot be well controlled by other demographic factors. Data are collected only by questionnaire and indepth interviews are not carried out with each individual. Researchers only examined respondents and did not pay attention to the environment external to the respondent, including the condition of the family at home, so they cannot predict the stress conditions caused by family and other factors.

\section{CONCLUSION}

Burnout syndrome is mostly caused by continuance and normative commitment. Personal factors have a relationship with burnout syndrome such as the level of education and the attitude of nurses in the type C hospital. The nurses' intention to turnover in hospital may be influenced by the level of emotional exhaustion. However, nurses in type $C$ hospitals prefer not to leave because they have to think about looking for job vacancies availability.

\section{Acknowledgement}

The authors would like to thank the respondents who helped in this research and all who have participated to finish this research up to writing this manuscript.

\section{Conflict of Interest}

This study does not have conflict of interest because this study was a self-study of the researcher.

\section{REFERENCES}

Aarssen, L. W., \& Crimi, L. (2016). Legacy, leisure and the 'work hard-Play hard' hypothesis. The Open Psychology Journal, 9. Retrieved from aarssenl@queensu.ca et al. (2017) Older and weaker or older and wiser: Exploring the drivers of performance differences between old and young adults on experiential learning tasks in the presence of veridical feedback., Dissertation Abstracts International Section A: Humanities and Social Sciences.

Abuaddous, H. Y., Al Sokkar, A. A. M. and Abualodous, B. I. (2018a) 'The impact of knowledge management on organizational performance', International Journal of Advanced Computer Science and Applications. doi: 
Abuaddous, H. Y., Al Sokkar, A. A. M. and Abualodous, B. I. (20I8b) 'The impact of knowledge management on organizational performance', International Journal of Advanced Computer Science and Applications, 9(4), Pp. 204-208. doi: 10.14569/IJACSA.20I8.090432.

Arrogante, O. and Aparicio-Zaldivar, E. (2017) 'Burnout and health among critical care professionals: The mediational role of resilience', Intensive and Critical Care Nursing, 42, Pp. 1I0-II5. doi: 10.1016/j.iccn.2017.04.010.

Beauvais, A. M. et al. (20II) 'Emotional intelligence and nursing performance among nursing students', Nurse Education Today, 3I(4), Pp. 396-40I. doi: I0.1016/j.nedt.2010.07.013.

Claramita, M. et al. (2016) 'Comparison of communication skills between trained and untrained students using a culturally sensitive nurse-client communication guideline in Indonesia', Nurse Education Today, 36, PP. 236-24I. doi: I0.10I6/j.nedt.20I5.10.022.

Fan, J. Y. et al. (20I5) 'Performance evaluation of nursing students following competencybased education', Nurse Education Today, 35(I), PP. 97-103. doi: 10.1016/j.nedt.2014.07.002.

Gibson, W. (2006) 'A Companion to Qualitative Research', Sociological Research Online, II(3), PP. 162-163. doi: I0.1I77/I3607804060II00305.

Kalani, S. et al. (2018) 'Interventions for physician burnout: A systematic review of systematic reviews', International Journal of Preventive Medicine, 9(I). doi: 10.4I03/ijpvm.JJPVM_255_18.

Kilgo, C. A., Ezell Sheets, J. K. and Pascarella, E. T. (2015) 'The link between high-impact practices and student learning: some longitudinal evidence', Higher Education, 69(4), pp. 509-525. doi: 10.1007/s I07340I4-9788-z.

Kim, H. and Suh, E. E. (2018) 'The Effects of an Interactive Nursing Skills Mobile Application on Nursing Students' Knowledge, Self-efficacy, and Skills Performance: A Randomized Controlled Trial', Asian Nursing Research. doi: I0.1016/j.anr.2018.01.00I.

Lestander, Ö., Lehto, N. and Engström, A.. (2016) 'Nursing students' perceptions of learning after high fidelity simulation: Effects of a Three-step Post-simulation Reflection Model', Nurse Education Today, 40, PP. 219-224. doi: I0.10I6/j.nedt.2016.03.0II.

De Oliveira, A. M. et al. (2018) 'The relationship between job satisfaction, burnout syndrome and depressive symptoms An analysis of professionals in a teaching hospital in Brazil', Medicine (United States). doi: 10.1097/MD.00000000000I3364.

De Paiva, L. C. et al. (2017) 'Burnout syndrome in health-care professionals in a university hospital', Clinics, 72(5), pp. 305-309. doi: $10.606 \mathrm{I} / \mathrm{clinics} / 20 \mathrm{I} 7(05) 08$.

Phiri, M., Heyns, T. and Coetzee, I. (2020) 'Patients' experiences of triage in an emergency department: A phenomenographic study', Applied Nursing Research, P. 15127I. doi: I0.1016/j.apnr.2020.15 I27I.

Prendergast, C., Ketteler, E. and Evans, G. (2017) 'Burnout in the plastic surgeon: Implications and interventions', Aesthetic Surgery Journal, 37(3), PP. 363-368. doi: 10.1093/asj/sjw I 58.

Ríos-Risquez, M. I. and García-Izquierdo, M. (2016) 'Patient satisfaction, stress and burnout in nursing personnel in emergency departments: A crosssectional study', International Journal of Nursing Studies, 59, Pp. 60-67. doi: 10.1016/j.jinurstu.2016.02.008.

Rodrigues, C. C. F. M., Santos, V. E. P. and Sousa, P. (2017) 'Patient safety and nursing: interface with stress and Burnout Syndrome', Revista brasileira de enfermagem, Pp. 1083-1088. doi: 10.1590/0034-7|67-2016-0194.

Shanafelt, T. D. and Noseworthy, J. H. (2017) 'Executive Leadership and Physician Wellbeing: Nine Organizational Strategies to Promote Engagement and Reduce Burnout', Mayo Clinic Proceedings, pp. 129146. doi: 10.1016/j.mayocp.2016.10.004.

Valero-Chillerón, M. J. et al. (2019) 'Burnout syndrome in nursing students: An observational study', Nurse Education Today, 76, PP. 38-43. doi: I0.1016/j.nedt.2019.0I.014.

VanFosson, C. A., Jones, T. L. and Yoder, L. H. (2016) 'Unfinished nursing care: An important performance measure for 
nursing care systems', Nursing Outlook, 64(2), PP. 124-136. doi: I0.1016/j.outlook.20I5.12.0I0.

Vidotti, V. et al. (2018) 'Burnout syndrome and shift work among the nursing staff, Revista Latino-Americana de Enfermagem, 26. doi: 10.1590/I5 18-8345.2550.3022.

Winasih, R., Nursalam, N. and Kurniawati, N. D. (20I5) 'Cultural Organization and Quality of Nursing Work Life on Nurses Performance and Job Satisfaction in Dr. Soetomo Hospital, Surabaya', Jurnal NERS,
10(2), P. 332. doi: I0.20473/jn.v I0i220 I5.332-342.

Wong, C. A., Cummings, G. G. and Ducharme, L. (20/3) 'The relationship between nursing leadership and patient outcomes: A systematic review update', Journal of Nursing Management, 2 I(5), pp. 709-724. doi: $10.11 \mathrm{I} /$ /jonm. 12116 .

Zelenik, D., Peršuh, T. and Jordan, T. (2016) 'Practical approach to nutritional support in nursing home', Clinical Nutrition ESPEN. doi: 10.1016/j.clnesp.2016.04.022. 